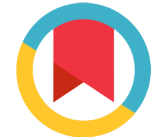

Check for updates
For correspondence:

alesaleh70@yahoo.com

Competing interests: The authors declare that no competing interests exist.

Received: 16 September 2017 Accepted: 06 November 2017 Published: 08 December 2017

Copyright The Author(s) 2017. This article is published with open access by BioMedPress.

This article is distributed under the terms of the Creative Commons Attribution License (CC-BY 4.0) which permits any use, distribution, and reproduction in any medium, provided the original author(s) and the source are credited.

\section{Incidence, mortality and risk factors of cervical cancer in the world}

\author{
Zohre Momenimovahed1', Hamid Salehiniya2,3,* \\ ${ }^{1}$ Department of Reproductive Health, School of Nursing and Midwifery, Tehran University \\ of Medical Sciences, Tehran, Iran \\ ${ }^{2}$ Zabol University of Medical Sciences, Zabol, Iran \\ ${ }^{3}$ Department of Epidemiology and Biostatistics, Tehran University of medical sciences, \\ Tehran, Iran
}

\section{Abstract}

Background: Cervical cancer imposes a huge global burden. To date, various studies have been conducted on the risk factors associated with cervical cancer. The aim of this study was to investigate the incidence, mortality, and geographical distribution of cervical cancer and its risk factors in the world. Methods: A literature search was conducted using PubMed, Web of sciences, Scopus, and Google Scholar to search for studies published between 2000 and 2017. The keywords used included cervical cancer, cervix uteri cancer, risk factor, incidence, mortality, and a combination of these terms. Results: The results of this study showed that the incidence of cervical cancer varies considerably between developed and developing countries. The findings of this study demonstrated that several factors including sexually transmitted infections, reproductive factors, hormonal influences, genetics and host factors are responsible for the incidence of cervical cancer. Conclusion: The results of this review study suggested that combination of biological, economic and health factors contributes to the incidence of cervical cancer. A large proportion cervical cancer can be prevented by prevention programs, lifestyle enhancement, smoking cessation, and timely and effective treatment of precancerous lesions.

\section{Keywords}

Cervical cancer, Incidence, Mortality, Risk factors, World 


\section{Introduction}

Cancer is currently the second leading cause of death, after heart disease, in the world (Torre et al., 2017), and this imposes a huge burden on societies (Cancer and Organization, 2016). Gynecological cancers are among the most common cancers in women. Cervical cancer is the most common type of gynecological cancer (Ferlay et al., 2015). Indeed, it is one of the major public health problems in the world and one of the top causes for disability-adjusted life-years (DALYs) (Fitzmaurice et al., 2015). Yet, cervical cancer is one of the most preventable cancers (Denny, 2012). Among women, it is a common cause of death, especially in women from less developed countries (Ferlay et al., 2015). However, from insight from research studies, the viral etiology of cervical cancer has become more well understood (Bosch and Muñoz, 2002). This cancer is among the most preventable cancers because of its slow progression, the presence of detectable lesions using cytology, and the introduction of effective treatments (Leyden et al., 2005).

In 2012, 528,000 new cases and 266,000 cases of death from cervical cancer were reported (Ferlay et al., 2015). Cervical cancer is a dynamic condition that has the highest incidence rate in young adults (Bruni et al., 2010). There has been a gradual decline in the incidence and mortality associated with cervical cancer worldwide. There has been a significant reduction in mortality associated with cervical cancer in developed countries as many cases are detected in a timely manner (Vaccarella et al., 2017). The results of several studies suggest that socioeconomic differences play an important role in the incidence, mortality and survival rate of cervical cancer (Akinyemiju et al., 2016; Ibfelt et al., 2013; Kim and Kang, 2016; Ueda et al., 2006). This is associated with a variety of factors, such as low access to screening (Leinonen et al., 2017), non-implementation of prevention programs (Chidyaonga-Maseko et al., 2015), ineffective and inadequate treatment, and poor sanitary conditions (Benard et al., 2008; Ganesan et al., 2015; Rossi et al., 2014).

Several epidemiological studies have revealed the role of various genetic factors in the incidence of cervical cancer (La Vecchia and Boccia, 2014; Roura et al., 2014; Silva et al., 2014). Among them are the infection of patients with one of the human papilloma virus (HPV) oncogene types; this factor is the most important etiological factor for induction of this cancer (Bosch and Muñoz, 2002; Plummer et al., 2016). Indeed, HPV is the most common sexually transmitted infection worldwide (Crosbie et al., 2013), and is strongly associated with cervical cancer. Over the past years, HPV testing (as a screening method) and vaccination were introduced for the prevention of cervical cancer (Heydari et al., 2017).

Identification of key risk factors continues to play an important role in the prevention of cervical cancer. To date, various studies have been conducted on the risk factors associated with cervical cancer (Durowade et al., 2012; Makuza et 
al., 2015; Ogunbowale and Lawoyin, 2008). The aim of this study was to investigate the incidence, mortality, and geographical distribution of cervical cancer and its risk factors in the world.

\section{Methods}

A literature search was conducted using PubMed, Web of sciences, Scopus, and Google Scholar to search for research studies published between 2000 and 2017. The keywords used included cervical cancer, cervix uteri cancer, risk factor, incidence, mortality, or a combination of these terms. The studies which clearly described the incidence and mortality rates of cervical cancer and/or related risk factors were included in our review study.

\section{Results}

\section{Incidence and mortality}

Cervical cancer is the fourth most common cancer in women and seventh most common cancer in general. In 2012, 528,000 new cases of cervical cancer were detected. There is a significant geographical difference in the incidence of cervical cancer. The majority of these cancers (about $85 \%$ ) are found in less developed areas (Vaccarella et al., 2017). The incidence and mortality of cervical cancer were found to be the highest in sub-Saharan Africa, Southeast Asia, Latin America, the Caribbeans, and Central and Eastern Europe. In Zimbabwe, Malawi and Uganda, the prevalence of cervical cancer is more than twice as compared to other regions. The lowest prevalence was found in Western Asia (Torre et al., 2016). Five countries had the highest incidence of cervical cancer cases in 2012; they were India $(122,844$ cases), China $(61,619)$, Indonesia $(20,928)$, Brazil $(18,503)$, and the Russian Federation (15,342) (Momenimovahed et al., 2017). It was reported, in 2012, that the age-standardized incidence of cervical cancer was 14 per 100,000 people worldwide, varying from 8.5 to 25.7 in countries with a high-to-low human development index. The incidence of cervical cancer shows a decreasing trend in most European and South American countries, North America and Oceania, and some Asian countries (such as Japan, China and India) (Vaccarella et al., 2013). Indeed, the decrease of cervical cancer incidence varies across regions (Vaccarella et al., 2017).

Cervical cancer is the third leading cause of cancer death among low-income and middle-income countries. Although rare among high-income countries (Torre et al., 2016), there were still approximately 266,000 deaths from cervical cancer worldwide in 2012, accounting for $7.5 \%$ of deaths from cancer in women. Approximately, 9 out of 10 cases of cervical cancer death occur in less developed regions. The mortality rate varies (up to 18-fold) between different regions of the world; it is less than 2 in 100,000 people in Western Asia, Western 
Europe, and Australia/New Zealand, but over 20 per 100,000 people in Melanesia, and Middle and Eastern Africa (Vaccarella et al., 2017). A quarter of the deaths from cervical cancer occur in India. Women in many of the high incidence areas, including Africa, are less likely to be screened for cervical cancer and, therefore, are most at risk for developing invasive cervical cancer (De Sanjosé et al., 2007). According to Momenimovahed et al. (2017), the mean age-standardized mortality rate for cervical uterine cancer is 6.8 in 100,000 people (range varies from 2.7 in 100,000 people to 16.6 in 100,000 people) in countries with a high-to-low human development index (Momenimovahed et al., 2017).

There are important variables in the incidence and mortality of cervical cancer in different regions of the world. These variables that account for observed geographical differences include access to screening programs (that allow for early detection and timely treatment of pre-cancerous lesions), prevalence of HPV (Torre et al., 2016; Vaccarella et al., 2013), and effective prevention (such as vaccination against HPV) (Torre et al., 2016). In high-income countries where screening programs have been introduced and implemented over decades, the incidence of cancer has reduced by $4 \%$ annually and by a total of $70 \%$. But the steady rate or even increased incidence of cervical cancer is still observed in countries with no screening, lack of quality screening, or low screening coverage (Torre et al., 2016). Socioeconomic differences among different countries play an important role in compliance with the screening programs (Monnat, 2014). Limited resources for implementing screening programs, lack of adequate knowledge, reduced access to health care (due to financial, physical or social constraints), and psychosocial stress all play an important role in screening and health promotion programs (Akinyemiju et al., 2016). As mentioned earlier, the differing prevalence of HPV is one of the most important factors for geographical variations in the incidence of cervical cancer. For instance, HPV is more prevalent in Africa and Latin America than it is in North America, Europe, and Asia (Bruni et al., 2010).

Vaccination against HPV has been introduced for many years to prevent and reduce the incidence of cervical cancer. However, there are several restrictions on using this effective method, with the most important being the cost of vaccination among developing countries (Gonçalves et al., 2014). Sex and reproductive factors as well as the quality of screening programs (laboratory and follow up) can also interfere with geographical differences (Vaccarella et al., 2013). Lack of accurate detection of lesions by cytology and lack of follow-up of abnormal cytology results are also responsible for high incidence of cervical cancer in less developed countries (Leyden et al., 2005).

\section{Risk factors}

Sexually transmitted infections (STI)

\section{- HPV}


The primary cause of pre-cancerous and cancerous cervical lesions is infection with a high-risk or oncogenic HPV types (Wardak, 2016). Most cases of cervical cancer occur as a result of infection with HPV 16 and 18. High-risk types, especially HPV 16, are found to be highly prevalent in human populations (Bruni et al., 2010). The infection is usually transmitted by sexual contact, causing squamous intraepithelial lesions. Most lesions disappear after 6 to 12 months due to immunological intervention. However, a small percentage of these lesions remain and can cause cancer (Zur Hausen, 2002).

The results of a meta-analysis showed that the highest prevalence of HPV occurs at the age of 25 years (De Sanjosé et al., 2007), which could be related to changes in sexual behavior (Crosbie et al., 2013). In a meta-analysis study, the bimodal distribution of cervical cancer in some regions has been studied. In this distribution, immediately after sexual intercourse, an outbreak of HPV can be observed, which is followed by a plateau at adult age; the second peak again is observed after 45 years of age (Bruni et al., 2010). Permanent infection with one of the high-risk types of HPV over time leads to the development of cervical intraepithelial neoplasia (CIN). The major mechanisms through which HPV contributes to carcinogenesis involve the activity of two viral oncoproteins, E6 and E7, which interfere with major tumor suppressor genes, P53 and retinoblastoma. In addition, E6 and E7 are associated with changes in host DNA and virus DNA methylation. Interactions of E6 and E7 with cellular proteins and DNA methylation modifications are associated with changes in key cellular pathways that regulate genetic integrity, cell adhesion, immune response, apoptosis, and cellular control (Galani and Christodoulou, 2009).

\section{- Chlamydia trachomatis}

In the study of Koskela et al., the results showed that previous infection with $C$. trachomatis contributes to an increased risk of cervical squamous cell carcinoma. In this study, C. trachomatis DNA was detected in $40 \%$ of invasive squamous cell carcinoma (Koskela et al., 2000). The results of a case-control study in 7 countries showed that serum antibodies of $C$. trachomatis are associated with a 1.8-fold increase in the risk of squamous cell carcinoma. This risk increases in women with higher antibody titers and in women under 55 years of age. C. trachomatis infection may increase the risk of squamous cell carcinoma by increasing host susceptibility to HPV or increasing HPV mediated effects. Inflammation that occurs as a result of chronic $C$. trachomatis infection can lead to the production of reactive oxygen species; hence, this can damage DNA and increase the risk of HPV-associated carcinogenesis. Furthermore, women with C. trachomatis may have a weakened ability to clear the HPV infection (Smith et al., 2004). Chlamydia can cause chronic inflammation, cervical hypertrophy, and squamous metaplasia. The metaplastic cells are the potential target cells for HPV. Therefore, as a result of infection with Chlamydia, apoptosis may be inhibited, there may be excessive expression of E6/E7 oncogenes, and cellular deformity may occur (Silva et al., 2014).

\section{- Human immunodeficiency virus (HIV)}


The risk of developing infection from high risk HPV types is higher in women with human immunodeficiency virus (HIV) (Ferenczy et al., 2003; Palefsky, 2007). The results of the studies on the relationship between HIV and cervical cancer suggested a higher rate of persistent HPV infection with multiple oncogene viruses (Mbulawa et al., 2010), more abnormal Papanicolau (Pap) smears, and higher incidence of CIN and invasive cervix carcinoma among people with HIV (Pantanowitz and Michelow, 2011).

\section{- Herpes simplex virus (HSV)}

There is relationship between HSV-2 antibodies in serum and invasive cervical cancer (or squamous cell carcinoma, adenocarcinoma, or adeno-squamous cervical carcinoma), as suggested by Smith et al. (Smith et al., 2002). However, these results have not been confirmed. For instance, a nested case control study by Lehtinen et al. concluded that HSV-2 does not play a role in the carcinogenesis of the cervix (Lehtinen et al., 2002).

\section{Reproductive and sexual factors}

\section{- Sexual partners}

An increased risk of cervical cancer is observed in people with multiple sexual partners (Castellsagué et al., 2003; Liu et al., 2015). This increase in risk is generally attributable to an increased risk of HPV infection. However, in the study by Liu et al., the risk of cancer was still high even after controlling for HPV infection. Therefore, other factors may contribute to the increased risk of cancer in people with multiple sexual partners (Liu et al., 2015). In the study by Edelstein et al., sexual experience at older ages was suggested to be associated with lower age of diagnosis (Edelstein et al., 2009). Also, early age at first intercourse is a risk factor for cervical cancer (Louie et al., 2009).

\section{- Parity}

Several studies have shown that full-term pregnancy increases the risk of invasive cervical cancer (Hildesheim et al., 2001; Kim et al., 2012; Muñoz et al., 2002). Moreover, high parity increases this risk of cancer in women (Muñoz et al., 2002). In a collaborative international epidemiological study of cervical cancer, a direct correlation was found between the risk of cervical cancer and parity; there was an inverse association between the risk of cervical cancer and the age of the mother at first pregnancy (González et al., 2006). Findings from the study by Hildesheim et al. are in agreement with the aforementioned study. Hildesheim et al. concluded that the risk of cervical cancer significantly increases with an increase in the number of deliveries (Hildesheim et al., 2001). In a cohort study with over 13 years of follow-up, delivery was the predictor of CIN 3. In this review study, too, delivery was observed to increase the risk of developing cervical cancer, especially among women with high risk HPV infection. In addition, no increase in pregnancy-associated risks was observed (Jensen et al., 2013). 


\section{- Oral contraceptive (OC) pills}

The current and recent use of combined oral contraceptive $(O C)$ methods is associated with an increased risk of cervical cancer (Hildesheim et al., 2001; Vanakankovit and Taneepanichskul, 2008). In an international collaborative epidemiological study of cervical cancer, the relative risk in current users increased with an increase in the duration of $O C$ use. It has been reported that the use of $O C$ method for 5 years or more can double the risk of cancer. However, there is a slight increase in the incidence of invasive cervical cancer in those who used only injectable progesterone for 5 years or more (Cancer, 2007).

In a multi-center case control study, among women who tested positive for HPV DNA, the risk of cervical cancer increased by 3 times if they have used OCP for 5 years or more. The results of this study showed that the risk of cancer does not depend on the first time use of OC pills (Moreno et al., 2002).

\section{Behavioral factors}

\section{- Smoking}

To date, various studies have shown that smoking is one of the most important risk factors for CIN 3 and invasive cervical cancer. There is a link between the history of smoking or current smoking, with cervical cancer (Fonseca-Moutinho, 2011; Hildesheim et al., 2001; Kim et al., 2012; Plummer et al., 2003). In a large cohort study, the risk of cancer was reduced by $50 \%$ among those who stopped smoking for 10 years when compared with those who continued to smoke. In this study, passive smoking was not associated with an increased risk of cervical cancer (Roura et al., 2014). Rather, the age of smoking is related to the incidence of cervical cancer. The results of the re-analysis of 23 epidemiological studies showed that the risk of squamous cell carcinoma of the cervix is related to cigarette smoking; with an increase in the number of cigarettes smoked there is a decrease in the age of smoking onset (González et al., 2006).

Smoking can increase the risk of cervical neoplasia through several mechanisms. One of the mechanisms is the local induction of immune suppression by tobacco metabolites. In addition, chemicals in cigarettes, such as nicotine and its metabolites, can cause DNA damage in squamous cells (Roura et al., 2014). Smoking can cause epigenetic changes in the epithelium of the cervix and contribute to the pathogenesis of neoplasia in the cervix and in many other parts of the body (Ma et al., 2011).

\section{- Obesity}

Obesity increases the risk of cervical carcinoma and is important in the incidence of cervical adenocarcinoma associated with hormonal risk factors (Lacey et al., 2003; Lee et al., 2013; Poorolajal and Jenabi, 2016). In a case control study, the risk of developing cervix adenocarcinoma in obese women with body mass 
index (BMI $\geq 30$ ) and overweight women (BMI $\geq 25$ ) was 2-fold higher than for other women (Lacey et al., 2003).

Due to the conversion of androgen to estrogen in the peripheral adipose tissue, obesity (especially after menopause) is considered to be a marker of increased sex hormones levels (Lacey et al., 2003). In addition to the role of obesity in the pathogenesis of cervical adenocarcinoma through hormonal activity, obese women are less likely to seek screening for cervical cancer (Ludman et al., 2010; Wee et al., 2000). There are different reasons for lower screening rates in this group. For one, obese women have delays in receiving services due to their negative physical image, shame, reduced respect by health care providers, and lack of willingness to lose weight (Friedman et al., 2012). Besides, obesity can be a sign of non-compliance with health behaviors, such as cervical cancer screening. Also, illnesses associated with obesity may limit the implementation of prophylactic services. The technical problems of performing Pap smears in obese women (such as their anatomy and lack of adequate equipment) can impact their willingness to seek effective screening (Ferrante et al., 2010; Friedman et al., 2012). Finally, there tends to be less advice given from doctors to obese women during routine screening; this is another reason for the lower rate of cervical cancer screening in obese individuals (Maruthur et al., 2009).

\section{Nutritional and dietary factors}

Cervical cancer occurs through a series of events, including HPV infection, persistence of HPV, and HPV-related lesions and progression towards cervical cancer (Munoz et al., 2009). The role of nutritional factors in the pathogenesis of cervical cancer has been taken into great account in recent years and several studies have evaluated this topic, though conflicting results have been obtained (González et al., 2011; Labani et al., 2009; Siegel et al., 2010). In one study, increased concentrations of $\alpha$ - and $\gamma$-tocopherol and higher nutritional intake of green vegetables, or dark green and yellow fruits, were associated with a $50 \%$ decrease in CIN 3 (Tomita et al., 2010). Therefore, receiving a healthy and balanced diet leads to higher levels of antioxidants and, therefore, can play a role in cervical neoplasia. In the study by Ghosh et al. (2008), a significant correlation was observed between higher intake of vitamin C, folate, vitamin $E$, beta-carotene, vitamin A, lycopene, and vegetarian foods with cervical cancer (Ghosh et al., 2008).

There are potential biological mechanisms regarding the protective effects of the nutritional factors against cervical cancer. Vitamins $C$ and $E$ play a role in increasing the mucosal response to infection and protection against free radicals and oxidants. Vitamins $C$ and $E$ can inhibit the formation of DNA adducts that are induced by cigarettes. In addition, antioxidants can regulate immune responses and reduce viral replication and gene expression (González et al., 2011). A case control study conducted by Hernandez et al. showed that thiamine, riboflavin, folate and vitamin B12 may provide protection against precancerous lesions of the cervix (Hernandez et al., 2003). A nested case-control 
study showed that frequent consumption of antioxidant-rich fruits is associated with a reduction in the risk of developing squamous intraepithelial lesion (Siegel et al., 2010). A study in 2008 showed that plant-based diets may play a protective role in reducing the risk of cervical cancer (Ghosh et al., 2008). In a case control study, significant reduction was observed in serum levels of antioxidants (e.g. beta-carotene, lycopene, zeaxanthin, retinol, and $\alpha$ and $\gamma$ tocopherol) in patients with CIN and cervical cancer (Cho et al., 2009).

\section{Inflammatory disease}

Several studies have investigated the role of inflammatory diseases in cervical cancer (Bernatsky et al., 2009; Kiss et al., 2010; Simon et al., 2015). The results of a population-based cohort study showed that women with rheumatoid arthritis and systemic lupus erythematosus are 1.5 times more likely to develop cervical dysplasia and cervical cancer (Kim et al., 2014). The results of a meta-analysis showed that there is a positive relationship between systemic lupus erythematosus and the risk of cervix neoplasia, and that these individuals are at greater risk for developing cervical cancer (Liu et al., 2010). For instance, in a research study by Al-Sherbeni et al., the rate of abnormal Pap smears was higher in patients with lupus (Al-Sherbeni et al., 2015).

It has been shown that the use of immunosuppressive agents, such as cyclophosphamide and azathioprine, may be associated with an increase in the incidence of cervical cancer in these individuals. On the other hand, the screening rate for cervical cancer is lower in people with lupus (Kiss et al., 2010).

\section{Host factors}

The role of host genetic sensitivity in the pathogenesis of cervical cancer has been investigated by several studies (Calhoun et al., 2002; Hildesheim and Wang, 2002; Rader, 2009). A case control study identified some of the host's genetic polymorphisms that may be associated with cervical cancer. Some polymorphisms were associated with cellular immune responses and/or antigenic processing (Calhoun et al., 2002). The results of a study by Wang et al. showed that host genetic variants may be responsible for determining the risk of cervical cancer pathogenesis in two important stages: the persistence of HPV and the progression of the disease (Wang et al., 2010). The findings of our review study also demonstrated a set of immune-deficiencies that are associated with carcinogenesis of HPV (Patel and Chiplunkar, 2009).

\section{Prevention and vaccination}

Understanding the role of HPV infection in cervical cancer has led to the development of immunogenic, safe and effective prophylactic vaccines (Crosbie et al., 2013). Vaccination against HPV has been available since 2006. These vaccines are available in many countries around the world, although vaccine coverage varies widely across different regions (Herrero et al., 2015). Sociocultural, health and political factors are the main barriers to the use of this 
vaccine among low-income and less developed countries (Wigle et al., 2013). Currently, three types of vaccines are available.

\section{- Quadrivalent vaccine (Gardasil)}

This vaccine consists of viral-like particles of L1 recombinant protein (major capsid protein) against HPV types 6, 11, 16 and 18 (Siddiqui and Perry, 2006).

\section{- Bivalent vaccine (Cervarix)}

This vaccine contains viral-like particles of recombinant L1 capsid proteins against HPV types 16 and 18 (Monie et al., 2008).

\section{- Nonavalent vaccine}

This vaccine was approved by the US Food and Drug Administration (FDA) in December 2014, and then approved by the European Medicine Agency in June 2015. This type of vaccine includes HPV types 6, 11, 16, 18, 31, 33, 45, 52 and 58 , and has similar performance to the bivalent and quadrivalent vaccines for different targets. This type of vaccine provides nearly $90 \%$ protection against cervical cancer and about $90 \%$ protection against genital warts (Bonanni et al., 2017).

These three types of vaccines primarily protect the individual against the HPV types present in the vaccine and provide only slight protection against other HPV types. These vaccines are recommended for women and men from the age of nine in two doses. For people over 15 years of age, three shots of the vaccine are usually given (Duclos, 2009).

\section{Conclusion}

The aim of this study was to understand the role of various risk factors in the incidence of cervical cancer and the burden associated with this cancer. The results of this study showed that the incidence of cervical cancer varies considerably between developed and developing countries. After the introduction of the Pap smear test and the use of prophylactic vaccines, the incidence of cervical cancer in the developed countries declined gradually. Significant differences in the incidence of cervical cancer among different countries can be attributed to the following factors: the existence, duration, and quality of screening programs; changes in the cervical cancer risk factors, especially those related to sexual behaviors that cause changes in exposure to HPV. Combination of biological, socio-economic and health factors contributes to the incidence of cervical cancer. A large proportion of cases of cervical cancer can be prevented by implementing prevention programs, lifestyle enhancement, smoking cessation and timely and effective treatment of pre-cancerous lesions. 


\title{
Abbreviations
}

\author{
BMI: Body Mass Index \\ CIN: Cervical Intraepithelial Neoplasia \\ DALYs: Disability-Adjusted Life-Years \\ FDA: Food and Drug Administration \\ HIV: Human Immunodeficiency Virus \\ HPV: Human Papilloma Virus \\ HSV: Herpes Simplex Virus \\ ICC: Invasive Cervical Cance \\ OC: Oral Contraceptive \\ STI: Sexually Transmitted Infections
}

\section{Author Contribution}

Zohre Momenimovahed: Literature review and data collection, drafted the first version and approved final version. Hamid Salehiniya: Literature review and writing the manuscript, drafted and edited the first version and approved final version.

\section{References}

Akinyemiju, T., Ogunsina, K., Sakhuja, S., Ogbhodo, V., \& Braithwaite, D. (2016). Lifecourse socioeconomic status and breast and cervical cancer screening: Analysis of the WHO9s Study on Global Ageing and Adult Health (SAGE). BMJ Open, 6(11), e012753. https://doi.org/10.1136/bmjopen-2016-012753

Al-Sherbeni, H. H., Fahmy, A. M., \& Sherif, N. (2015). Predisposition to cervical atypia in systemic lupus erythematosus: A clinical and cytopathological study. Autoimmune

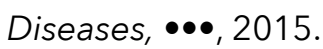

Benard, V. B., Johnson, C. J., Thompson, T. D., Roland, K. B., Lai, S. M., Cokkinides, V., ... Weir, H. K. (2008). Examining the association between socioeconomic status and potential human papillomavirus-associated cancers. Cancer, 113(S10), 2910-2918. https://doi.org/10.1002/cncr.23742

Bernatsky, S., Ramsey-Goldman, R., \& Clarke, A. E. (2009). Malignancy in systemic lupus erythematosus: What have we learned? Best Practice \& Research. Clinical Rheumatology, 23(4), 539-547. https://doi.org/10.1016/j.berh.2008.12.007

Bonanni, P., Zanella, B., Santomauro, F., Lorini, C., Bechini, A., \& Boccalini, S. (2017). Safety and perception: What are the greatest enemies of HPV vaccination programmes? Vaccine. https://doi.org/10.1016/j.vaccine.2017.05.071

Bosch, F. X., \& Muñoz, N. (2002). The viral etiology of cervical cancer. Virus Research, 89(2), 183-190. https://doi.org/10.1016/S0168-1702(02)00187-9

Bruni, L., Diaz, M., Castellsagué, M., Ferrer, E., Bosch, F. X., \& de Sanjosé, S. (2010). Cervical human papillomavirus prevalence in 5 continents: Meta-analysis of 1 million women with normal cytological findings. The Journal of Infectious Diseases, 202(12), 1789-1799. https://doi.org/10.1086/657321 
Calhoun, E. S., McGovern, R. M., Janney, C. A., Cerhan, J. R., Iturria, S. J., Smith, D. I., . . Persing, D. H. (2002). Host genetic polymorphism analysis in cervical cancer. Clinical Chemistry, 48, 1218-1224.

Cancer, I.A.f.R.o., and Organization, W.H. (2016). GLOBOCAN 2012: Cancer Incidence and Mortality Worldwide.

Cancer, I. C. E. S. C. (2007). Cervical cancer and hormonal contraceptives: Collaborative reanalysis of individual data for 16573 women with cervical cancer and 35509 women without cervical cancer from 24 epidemiological studies. Lancet, 370(9599), 16091621. https://doi.org/10.1016/S0140-6736(07)61684-5

Castellsagué, X., Bosch, F.X., and Muñoz, N. (2003). The male role in cervical cancer. salud pública de méxico 45, 345-353.

Chidyaonga-Maseko, F., Chirwa, M. L., \& Muula, A. S. (2015). Underutilization of cervical cancer prevention services in low and middle income countries: A review of

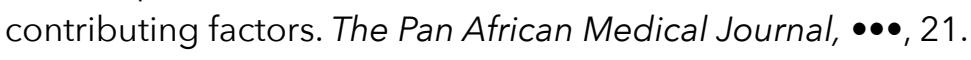

Cho, H., Kim, M. K., Lee, J. K., Son, S. K., Lee, K.-B., Lee, J.-M., . . Kim, J.-H. (2009). Relationship of serum antioxidant micronutrients and sociodemographic factors to cervical neoplasia: A case-control study. Clinical Chemistry and Laboratory Medicine, 47(8), 1005-1012. https://doi.org/10.1515/CCLM.2009.221

Crosbie, E. J., Einstein, M. H., Franceschi, S., \& Kitchener, H. C. (2013). Human papillomavirus and cervical cancer. Lancet, 382(9895), 889-899. https://doi.org/ 10.1016/S0140-6736(13)60022-7

De Sanjosé, S., Diaz, M., Castellsagué, X., Clifford, G., Bruni, L., Muñoz, N., \& Bosch, F. X. (2007). Worldwide prevalence and genotype distribution of cervical human papillomavirus DNA in women with normal cytology: A meta-analysis. The Lancet. Infectious Diseases, 7(7), 453-459. https://doi.org/10.1016/S1473-3099(07)70158-5

Denny, L. (2012). Cervical cancer: Prevention and treatment. Discovery Medicine, 14, 125-131.

Duclos, P. (2009). Human papillomavirus vaccines: WHO position paper. Biologicals. Durowade, K., Osagbemi, G., Salaudeen, A., Musa, O., Akande, T., Babatunde, O., . . . Ibrahim, O. (2012). Prevalence and risk factors of cervical cancer among women in an urban community of Kwara State, north central Nigeria. Journal of Preventive Medicine and Hygiene, $\bullet \bullet \bullet, 53$.

Edelstein, Z. R., Madeleine, M. M., Hughes, J. P., Johnson, L. G., Schwartz, S. M., Galloway, D. A., .. Koutsky, L. A. (2009). Age of diagnosis of squamous cell cervical carcinoma and early sexual experience. Cancer Epidemiology and Prevention Biomarkers, 18(4), 1070-1076. https://doi.org/10.1158/1055-9965.EPI-08-0707

Ferenczy, A., Coutlée, F., Franco, E., \& Hankins, C. (2003). Human papillomavirus and HIV coinfection and the risk of neoplasias of the lower genital tract: A review of recent developments. Canadian Medical Association Journal, 169, 431-434.

Ferlay, J., Soerjomataram, I., Dikshit, R., Eser, S., Mathers, C., Rebelo, M., . . Bray, F. (2015). Cancer incidence and mortality worldwide: Sources, methods and major patterns in GLOBOCAN 2012. International Journal of Cancer, $\bullet \bullet, 136$.

Ferrante, J. M., Fyffe, D. C., Vega, M. L., Piasecki, A. K., Ohman-Strickland, P. A., \& Crabtree, B. F. (2010). Family physicians' barriers to cancer screening in extremely obese patients. Obesity (Silver Spring, Md.), 18(6), 1153-1159. https://doi.org/10.1038/ oby.2009.481

Fitzmaurice, C., Dicker, D., Pain, A., Hamavid, H., Moradi-Lakeh, M., Maclntyre, M. F., . . Wolfe, C. (2015). The global burden of cancer 2013. JAMA Oncology, 1(4), 505-527. https://doi.org/10.1001/jamaoncol.2015.0735 
Fonseca-Moutinho, J. A. (2011). Smoking and cervical cancer. ISRN Obstetrics and Gynecology, $\bullet \bullet, 2011$.

Friedman, A. M., Hemler, J. R., Rossetti, E., Clemow, L. P., \& Ferrante, J. M. (2012). Obese women's barriers to mammography and pap smear: The possible role of personality. Obesity (Silver Spring, Md.), 20(8), 1611-1617. https://doi.org/10.1038/oby.2012.50 Galani, E., \& Christodoulou, C. (2009). Human papilloma viruses and cancer in the post-vaccine era. Clinical Microbiology and Infection, 15(11), 977-981. https://doi.org/ 10.1111/j.1469-0691.2009.03032.x

Ganesan, S., Subbiah, V.N., and Michael, J.C.J. (2015). Associated factors with cervical pre-malignant lesions among the married fisher women community at Sadras, Tamil Nadu. Asia-Pacific journal of oncology nursing 2, 42.

Ghosh, C., Baker, J. A., Moysich, K. B., Rivera, R., Brasure, J. R., \& McCann, S. E. (2008). Dietary intakes of selected nutrients and food groups and risk of cervical cancer. Nutrition and Cancer, 60(3), 331-341. https://doi.org/10.1080/01635580701861769

Gonçalves, A. K., Cobucci, R. N., Rodrigues, H. M., Melo, A. G., \& Giraldo, P. C. (2014). Safety, tolerability and side effects of human papillomavirus vaccines: A systematic quantitative review. The Brazilian Journal of Infectious Diseases, 18(6), 651-659. https:// doi.org/10.1016/j.bjid.2014.02.005

González, A., Colin, D., Franceschi, S., Goodill, A., Green, J., Peto, J., . . Skegg, D. (2006). Carcinoma of the cervix and tobacco smoking: Collaborative reanalysis of individual data on 13,541 women with carcinoma of the cervix and 23,017 women without carcinoma of the cervix from 23 epidemiological studies. International Journal of Cancer, 118(6), 1481-1495. https://doi.org/10.1002/ijc.21493

González, C. A., Travier, N., Luján-Barroso, L., Castellsagué, X., Bosch, F. X., Roura, E., ... Pala, V. (2011). Dietary factors and in situ and invasive cervical cancer risk in the European prospective investigation into cancer and nutrition study. International Journal of Cancer, 129(2), 449-459. https://doi.org/10.1002/ijc.25679

Hernandez, B. Y., McDuffie, K., Wilkens, L. R., Kamemoto, L., \& Goodman, M. T. (2003). Diet and premalignant lesions of the cervix: Evidence of a protective role for folate, riboflavin, thiamin, and vitamin B12. Cancer Causes \& Control, 14(9), 859-870. https:// doi.org/10.1023/B:CACO.0000003841.54413.98

Herrero, R., González, P., \& Markowitz, L. E. (2015). Present status of human papillomavirus vaccine development and implementation. The Lancet. Oncology, 16(5), e206-e216. https://doi.org/10.1016/S1470-2045(14)70481-4

Heydari, N., Oskouee, M. A., Vaezi, T., Shoja, Z., Esmaeili, H. A., Hamkar, R., ... Jalilvand, S. (2017). Type-specific human papillomavirus prevalence in cervical intraepithelial neoplasia and cancer in Iran. Journal of Medical Virology.

Hildesheim, A., Herrero, R., Castle, P. E., Wacholder, S., Bratti, M., Sherman, M., . . . Rodríguez, A. C. (2001). HPV co-factors related to the development of cervical cancer: Results from a population-based study in Costa Rica. British Journal of Cancer, 84(9), 1219-1226. https://doi.org/10.1054/bjoc.2001.1779

Hildesheim, A., \& Wang, S. S. (2002). Host and viral genetics and risk of cervical cancer: A review. Virus Research, 89(2), 229-240. https://doi.org/10.1016/ $\underline{\text { S0168-1702(02)00191-0 }}$

Ibfelt, E., Kjaer, S., Høgdall, C., Steding-Jessen, M., Kjaer, T., Osler, M., ... Dalton, S. O. (2013). 'Socioeconomic position and survival after cervical cancer: Influence of cancer stage, comorbidity and smoking among Danish women diagnosed between 2005 and 2010. British Journal of Cancer, 109(9), 2489-2495. https://doi.org/10.1038/bjc. $\underline{2013.558}$ 
Jensen, K., Schmiedel, S., Norrild, B., Frederiksen, K., Iftner, T., \& Kjaer, S. (2013). Parity as a cofactor for high-grade cervical disease among women with persistent human papillomavirus infection: A 13-year follow-up. British Journal of Cancer, 108(1), 234239. https://doi.org/10.1038/bjc. 2012.513

Kim, J., Kim, B. K., Lee, C. H., Seo, S. S., Park, S.-Y., \& Roh, J.-W. (2012). Human papillomavirus genotypes and cofactors causing cervical intraepithelial neoplasia and cervical cancer in Korean women. International Journal of Gynecological Cancer, 22, 1570-1576.

Kim, J.-Y., \& Kang, H.-T. (2016). Association between Socioeconomic Status and Cancer Screening in Koreans over 40 Years in Age Based on the 2010-2012 Korean National Health and Nutrition Examination Survey. Korean Journal of Family Medicine, 37(5), 287-292. https://doi.org/10.4082/kjfm.2016.37.5.287

Kim, S.C., Glynn, R.J., Giovannucci, E., Hernández-Díaz, S., Liu, J., Feldman, S., Karlson, E.W., Schneeweiss, S., and Solomon, D.H. (2014). Risk of high-grade cervical dysplasia and cervical cancer in women with systemic inflammatory diseases: a population-based cohort study. Annals of the rheumatic diseases, annrheumdis-2013-204993.

Kiss, E., Kovacs, L., \& Szodoray, P. (2010). Malignancies in systemic lupus erythematosus. Autoimmunity Reviews, 9(4), 195-199. https://doi.org/10.1016/j.autrev.2009.07.004

Koskela, P., Anttila, T., Bjørge, T., Brunsvig, A., Dillner, J., Hakama, M., . . Lenner, P. (2000). Chlamydia trachomatis infection as a risk factor for invasive cervical cancer. International Journal of Cancer, 85(1), 35-39. https://doi.org/10.1002/ (SICI)1097-0215(20000101)85:1<35::AID-IJC6>3.0.CO:2-A

La Vecchia, C., \& Boccia, S. (2014). Oral contraceptives, human papillomavirus and cervical cancer. European Journal of Cancer Prevention, 23(2), 110-112. https://doi.org/ 10.1097/CEJ.0000000000000000

Labani, L., Andallu, B., Meera, M., Asthana, S., \& Satyanarayana, L. (2009). Food consumption pattern in cervical carcinoma patients and controls. Indian Journal of Medical and Paediatric Oncology : Official Journal of Indian Society of Medical \& Paediatric Oncology, 30(2), 71. https://doi.org/10.4103/0971-5851.60051

Lacey, J. V., Swanson, C. A., Brinton, L. A., Altekruse, S. F., Barnes, W. A., Gravitt, P. E., . . Mortel, R. (2003). Obesity as a potential risk factor for adenocarcinomas and squamous cell carcinomas of the uterine cervix. Cancer, 98(4), 814-821. https://doi.org/10.1002/ cncr.11567

Lee, J. K., So, K. A., Piyathilake, C. J., \& Kim, M. K. (2013). Mild obesity, physical activity, calorie intake, and the risks of cervical intraepithelial neoplasia and cervical cancer. PLoS One, 8(6), e66555. https://doi.org/10.1371/journal.pone.0066555

Lehtinen, M., Koskela, P., Jellum, E., Bloigu, A., Anttila, T., Hallmans, G., . . Dillner, J. (2002). Herpes simplex virus and risk of cervical cancer: A longitudinal, nested casecontrol study in the nordic countries. American Journal of Epidemiology, 156(8), 687692. https://doi.org/10.1093/aje/kwf098

Leinonen, M. K., Campbell, S., Klungsøyr, O., Lönnberg, S., Hansen, B. T., \& Nygård, M. (2017). Personal and provider level factors influence participation to cervical cancer screening: A retrospective register-based study of 1.3 million women in Norway. Preventive Medicine, 94, 31-39. https://doi.org/10.1016/j.ypmed.2016.11.018

Leyden, W. A., Manos, M. M., Geiger, A. M., Weinmann, S., Mouchawar, J., Bischoff, K., ... Taplin, S. H. (2005). Cervical cancer in women with comprehensive health care access: Attributable factors in the screening process. Journal of the National Cancer Institute, 97(9), 675-683. https://doi.org/10.1093/jnci/dji115 
Liu, H., Ding, Q., Yang, K., Zhang, T., Li, G., \& Wu, G. (2010). Meta-analysis of systemic lupus erythematosus and the risk of cervical neoplasia. Rheumatology, 50(2), 343-348. https://doi.org/10.1093/rheumatology/keq304

Liu, Z.-C., Liu, W.-D., Liu, Y.-H., Ye, X.-H., \& Chen, S.-D. (2015). Multiple sexual partners as a potential independent risk factor for cervical cancer: A meta-analysis of epidemiological studies. Asian Pacific Journal of Cancer Prevention, 16(9), 3893-3900. https://doi.org/10.7314/APJCP.2015.16.9.3893

Louie, K., De Sanjose, S., Diaz, M., Castellsague, X., Herrero, R., Meijer, C., ... Bosch, F. (2009). Early age at first sexual intercourse and early pregnancy are risk factors for cervical cancer in developing countries. British Journal of Cancer, 100(7), 1191-1197. https://doi.org/10.1038/sj.bjc.6604974

Ludman, E. J., Ichikawa, L. E., Simon, G. E., Rohde, P., Arterburn, D., Operskalski, B. H., . . Jeffery, R. W. (2010). Breast and cervical cancer screening: Specific effects of depression and obesity. American Journal of Preventive Medicine, 38(3), 303-310. https://doi.org/10.1016/j.amepre.2009.10.039

Ma, Y., Collins, S., Young, L. S., Murray, P. G., \& Woodman, C. B. (2011). Smoking initiation is followed by the early acquisition of epigenetic change in cervical epithelium: A longitudinal study. British Journal of Cancer, 104(9), 1500-1504. https:// doi.org/10.1038/bjc.2011.113

Makuza, J. D., Nsanzimana, S., Muhimpundu, M. A., Pace, L. E., Ntaganira, J., \& Riedel, D. J. (2015). Prevalence and risk factors for cervical cancer and pre-cancerous lesions in

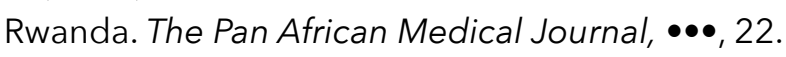

Maruthur, N. M., Bolen, S. D., Brancati, F. L., \& Clark, J. M. (2009). The association of obesity and cervical cancer screening: A systematic review and meta-analysis. Obesity (Silver Spring, Md.), 17(2), 375-381. https://doi.org/10.1038/oby.2008.480

Mbulawa, Z. Z., Marais, D. J., Johnson, L. F., Boulle, A., Coetzee, D., \& Williamson, A.-L. (2010). Influence of human immunodeficiency virus and CD4 count on the prevalence of human papillomavirus in heterosexual couples. The Journal of General Virology, 91(12), 3023-3031. https://doi.org/10.1099/vir.0.020669-0

Momenimovahed, Z., Ghoncheh, M., Pakzad, R., Hasanpour, H., \& Salehiniya, H. (2017). Incidence and mortality of uterine cancer and relationship with Human Development Index in the world. CUKUROVA MEDICAL JOURNAL, 42, 233-240. https://doi.org/ 10.17826/cutf.322865

Monie, A., Hung, C.-F., Roden, R., \& Wu, T. C. (2008). Cervarix ${ }^{\mathrm{TM}}$ : A vaccine for the prevention of HPV 16, 18-associated cervical cancer. Biologics, 2, 107.

Monnat, S. M. (2014). Race/ethnicity and the socioeconomic status gradient in women's cancer screening utilization: A case of diminishing returns? Journal of Health Care for the Poor and Underserved, 25(1), 332-356. https://doi.org/10.1353/hpu.2014.0050

Moreno, V., Bosch, F. X., Muñoz, N., Meijer, C. J., Shah, K. V., Walboomers, J. M., . . Franceschi, S. (2002). Effect of oral contraceptives on risk of cervical cancer in women with human papillomavirus infection: The IARC multicentric case-control study. Lancet, 359(9312), 1085-1092. https://doi.org/10.1016/S0140-6736(02)08150-3

Muñoz, N., Franceschi, S., Bosetti, C., Moreno, V., Herrero, R., Smith, J. S., ... Bosch, F. X. (2002). Role of parity and human papillomavirus in cervical cancer: The IARC multicentric case-control study. Lancet, 359(9312), 1093-1101. https://doi.org/ 10.1016/S0140-6736(02)08151-5

Munoz, N., Hernandez-Suarez, G., Mendez, F., Molano, M., Posso, H., Moreno, V., . . . Munoz, A. (2009). Persistence of HPV infection and risk of high-grade cervical intraepithelial neoplasia in a cohort of Colombian women. British Journal of Cancer, 100(7), 1184-1190. https://doi.org/10.1038/sj.bjc.6604972 
Ogunbowale, T., \& Lawoyin, T. O. (2008). Cervical cancer risk factors and predictors of cervical dysplasia among women in south-west Nigeria. The Australian Journal of Rural Health, 16(6), 338-342. https://doi.org/10.1111/j.1440-1584.2008.01013.x

Palefsky, J. (2007). Human papillomavirus infection in HIV-infected persons. Topics in HIV medicine: a publication of the International AIDS Society, USA 15, 130-133.

Pantanowitz, L., \& Michelow, P. (2011). Review of human immunodeficiency virus (HIV) and squamous lesions of the uterine cervix. Diagnostic Cytopathology, 39(1), 65-72. https://doi.org/10.1002/dc.21364

Patel, S., \& Chiplunkar, S. (2009). Host immune responses to cervical cancer. Current Opinion in Obstetrics \& Gynecology, 21(1), 54-59. https://doi.org/10.1097/GCO. 0b013e32831a9890

Plummer, M., de Martel, C., Vignat, J., Ferlay, J., Bray, F., \& Franceschi, S. (2016). Global burden of cancers attributable to infections in 2012: A synthetic analysis. The Lancet. Global Health, 4(9), e609-e616. https://doi.org/10.1016/S2214-109X(16)30143-7

Plummer, M., Herrero, R., Franceschi, S., Meijer, C. J., Snijders, P., Bosch, F. X., . . Muñoz, N. (2003). Smoking and cervical cancer: Pooled analysis of the IARC multi-centric casecontrol study. Cancer Causes \& Control, 14(9), 805-814. https://doi.org/10.1023/ B:CACO.0000003811.98261.3e

Poorolajal, J., \& Jenabi, E. (2016). The association between BMI and cervical cancer risk: A meta-analysis. European Journal of Cancer Prevention, 25(3), 232-238. https:// doi.org/10.1097/CEJ.0000000000000164

Rader, J. S. (2009). Host and viral genetics and risk of cervical cancer. In The Role of Genetics in Breast and Reproductive Cancers (pp. 263-284). Springer. https://doi.org/ 10.1007/978-1-4419-0477-5_12

Rossi, P. G., Baldacchini, F., \& Ronco, G. (2014). The possible effects on socio-economic inequalities of introducing HPV testing as primary test in cervical cancer screening programs. Frontiers in Oncology, $\bullet \bullet, 4$.

Roura, E., Castellsagué, X., Pawlita, M., Travier, N., Waterboer, T., Margall, N., .. Gram, I. T. (2014). Smoking as a major risk factor for cervical cancer and pre-cancer: Results from the EPIC cohort. International Journal of Cancer, 135(2), 453-466. https://doi.org/ 10.1002/ijc.28666

Siddiqui, M. A. A., \& Perry, C. M. (2006). Human papillomavirus quadrivalent (types 6, $11,16,18)$ recombinant vaccine (Gardasil $\left.{ }^{\circledR}\right)$. Drugs, 66(9), 1263-1271. https://doi.org/ 10.2165/00003495-200666090-00008

Siegel, E. M., Salemi, J. L., Villa, L. L., Ferenczy, A., Franco, E. L., \& Giuliano, A. R. (2010). Dietary consumption of antioxidant nutrients and risk of incident cervical intraepithelial neoplasia. Gynecologic Oncology, 118(3), 289-294. https://doi.org/10.1016/j.ygyno. 2010.05.022

Silva, J., Cerqueira, F., \& Medeiros, R. (2014). Chlamydia trachomatis infection: Implications for HPV status and cervical cancer. Archives of Gynecology and Obstetrics, 289(4), 715-723. https://doi.org/10.1007/s00404-013-3122-3

Simon, T. A., Thompson, A., Gandhi, K. K., Hochberg, M. C., \& Suissa, S. (2015). Incidence of malignancy in adult patients with rheumatoid arthritis: A meta-analysis. Arthritis Research \& Therapy, 17(1), 212. https://doi.org/10.1186/s13075-015-0728-9 Smith, J. S., Bosetti, C., Muñoz, N., Herrero, R., Bosch, F. X., Eluf-Neto, J., . . Peeling, R. W. (2004). Chlamydia trachomatis and invasive cervical cancer: A pooled analysis of the IARC multicentric case-control study. International Journal of Cancer, 111(3), 431-439. https://doi.org/10.1002/ijc.20257

Smith, J. S., Herrero, R., Bosetti, C., Munoz, N., Bosch, F. X., Eluf-Neto, J., . . Franceschi, S. (2002). Herpes simplex virus-2 as a human papillomavirus cofactor in the etiology of 
invasive cervical cancer. Journal of the National Cancer Institute, 94(21), 1604-1613. https://doi.org/10.1093/jnci/94.21.1604

Tomita, L. Y., Costa, M. C., Andreoli, M. A. A., Villa, L. L., Franco, E. L., \& Cardoso, M. A. (2010). Diet and serum micronutrients in relation to cervical neoplasia and cancer among low-income Brazilian women. International Journal of Cancer, 126(3), 703-714. https://doi.org/10.1002/ijc.24793

Torre, L. A., Islami, F., Siegel, R. L., Ward, E. M., \& Jemal, A. (2017). Global cancer in women: burden and trends. AACR.

Torre, L. A., Siegel, R. L., Ward, E. M., \& Jemal, A. (2016). Global cancer incidence and mortality rates and trends-An update. Cancer Epidemiology and Prevention Biomarkers, 25(1), 16-27. https://doi.org/10.1158/1055-9965.EPI-15-0578

Ueda, K., Kawachi, I., \& Tsukuma, H. (2006). Cervical and corpus cancer survival disparities by socioeconomic status in a metropolitan area of Japan. Cancer Science, 97(4), 283-291. https://doi.org/10.1111/j.1349-7006.2006.00179.x

Vaccarella, S., Laversanne, M., Ferlay, J., \& Bray, F. (2017). Cervical cancer in Africa, Latin America and the Caribbean, and Asia: Regional inequalities and changing trends. International Journal of Cancer, 141(10), 1997-2001. https://doi.org/10.1002/ijc.30901 Vaccarella, S., Lortet-Tieulent, J., Plummer, M., Franceschi, S., \& Bray, F. (2013). Worldwide trends in cervical cancer incidence: Impact of screening against changes in disease risk factors. European Journal of Cancer, 49(15), 3262-3273. https://doi.org/ 10.1016/j.ejca.2013.04.024

Vanakankovit, N., and Taneepanichskul, S. (2008). Effect of oral contraceptives on risk of cervical cancer. Medical journal of the Medical Association of Thailand 91, 7.

Wang, S. S., Gonzalez, P., Yu, K., Porras, C., Li, Q., Safaeian, M., . . Schiffman, M. (2010). Common genetic variants and risk for HPV persistence and progression to cervical cancer. PLoS One, 5(1), e8667. https://doi.org/10.1371/journal.pone.0008667

Wardak, S. (2016). Human Papillomavirus (HPV) and cervical cancer. Medycyna Doswiadczalna i Mikrobiologia, 68, 73.

Wee, C. C., McCarthy, E. P., Davis, R. B., \& Phillips, R. S. (2000). Screening for cervical and breast cancer: Is obesity an unrecognized barrier to preventive care? Annals of Internal Medicine, $132(9), 697-704$. https://doi.org/ 10.7326/0003-4819-132-9-200005020-00003

Wigle, J., Coast, E., \& Watson-Jones, D. (2013). Human papillomavirus (HPV) vaccine implementation in low and middle-income countries (LMICs): Health system experiences and prospects. Vaccine, 31(37), 3811-3817. https://doi.org/10.1016/ j.vaccine.2013.06.016

Zur Hausen, H. (2002). Papillomaviruses and cancer: From basic studies to clinical application. Nature Reviews. Cancer, 2(5), 342-350. https://doi.org/10.1038/nrc798 